\title{
Apoptotic activity of a novel synthetic cantharidin analogue on hepatoma cell lines
}

\author{
STANTON HON LUNG KOK ${ }^{1}$, CHUNG HIN CHUI ${ }^{1,2}$, WING SZE LAM ${ }^{1}$, JIEN CHEN ${ }^{1}$, FUNG YI LAU ${ }^{2}$, \\ GREGORY YIN MING CHENG ${ }^{2}$, RAYMOND SIU MING WONG ${ }^{2}$, PAUL PO SAN LAI ${ }^{3}$, \\ THOMAS WAI TONG LEUNG ${ }^{4}$, JOHNNY CHEUK ON TANG ${ }^{1}$ and ALBERT SUN CHI CHAN ${ }^{1}$
}

\begin{abstract}
${ }^{1}$ Cancer Drug and Development Centre, Central Laboratory of the Institute of Molecular Technology for Drug Discovery and Synthesis, State Key Laboratory of Chinese Medicine and Molecular Pharmacology, Department of Applied Biology and Chemical Technology, The Hong Kong Polytechnic University; Departments of ${ }^{2}$ Medicine and Therapeutics, and ${ }^{3}$ Surgery, Prince of Wales Hospital, The Chinese University of Hong Kong; ${ }^{4}$ Oncology Centre,

The Hong Kong Sanatorium and Hospital, Hong Kong, P.R. China
\end{abstract}

Received December 5, 2005; Accepted January 24, 2006

\begin{abstract}
Cantharidin isolated from Mylabris caraganae and other insects is used traditionally as an anti-cancer drug. However, its toxicity on the renal system and suppression effect on bone marrow limits its clinical usage. Recently, we have synthesized two cantharidin analogues, CAN 029 (compound 2) and CAN 030 (compound 3). Although both showed an apoptotic induction ability on cancer cells, they were still relatively toxic towards non-malignant haematological disordered bone marrow. Based on the principle structure of cantharidin, we have further chemically synthesized another analogue, CAN 032. The cytotoxic activity of this analogue was screened on both Hep3B hepatocellular carcinoma and SK-Hep-1 liver adenocarcinoma cell lines by [3-(4,5-dimethylthiazol-2-yl)-5-(3-carboxymethoxyphenyl)2-(4-sulfophenyl)-2H-tetrazolium] (MTS) assay. Morphological changes of hepatoma cell lines were recorded under an inverted microscope. The possible tolerance of these analogues was further investigated using non-malignant haematological bone marrow primary culture. CAN 032 showed a significant cytotoxic response on both hepatoma cell lines in which the potencies were comparable to that of cantharidin. Further screening on the bone marrow tolerance revealed that compound CAN 032 showed a relatively less toxic effect. Phase contrast microscopy demonstrated that cell shrinkage, rounding, loss of adherent property and loss of colonyformation ability were induced. The dose-dependence of the
\end{abstract}

Correspondence to: Dr Johnny Cheuk On Tang, Department of Applied Biology and Chemical Technology, The Hong Kong Polytechnic University, Hung Hom, Hong Kong, P.R. China

E-mail: bccotang@inet.polyu.edu.hk

Key words: apoptosis, cantharidin, hepatoma response of CAN 032 on Hep3B was further assayed by DNA fragmentation gel electrophoresis. The $\mathrm{G}_{1}$ peak of Hep3B cells was reduced. Chemically synthesized CAN 032 may provide an improved therapeutic advantage over traditional cantharidin.

\section{Introduction}

Hepatocellular carcinoma is commonly observed in East Asia. Even though tumour resection could enhance disease-free survival, some hepatocellular carcinoma remain unresectable due to the tumour size/volume and their complicated location. Thus, chemotherapy remains a major therapeutic pathway which could either reduce the tumour size or achieve complete remission (1).

Cantharidin has been used for the treatment of tumours, including hepatocellular carcinoma, clinically. It can be isolated naturally from many types of commonly found insects, including Mylabris caraganae. However, the highly toxic nature limits its usage $(2,3)$. Therefore, many modified cantharidin analogues are synthesized chemically in order to achieve a comparable antitumour property to the mother compound but simultaneously produce a less toxic effect on non-cancer cells.

Recently, we synthesized two cantharidin analogues and, although both of them showed apoptotic induction potential on cancer cells, they were still relatively toxic towards nonmalignant haematological disordered bone marrow (4). Based on the principle structure of cantharidin, we have synthesized another analogue (CAN 032) by further chemical modifications. We have tested its in vitro cytotoxicity on two hepatoma cell lines, Hep3B and SK-Hep-1. CAN 032 showed a potential cytotoxic effect on these hepatoma cell lines similar to that of cantharidin. The tolerance test of these potential antitumour compounds was carried out using primary culture of nonmalignant haematological bone marrow samples. Cell cycle arrest was investigated. Both the morphological investigation and DNA fragmentation formation were studied by inverted microscopy and DNA electrophoretic analysis. Our results 


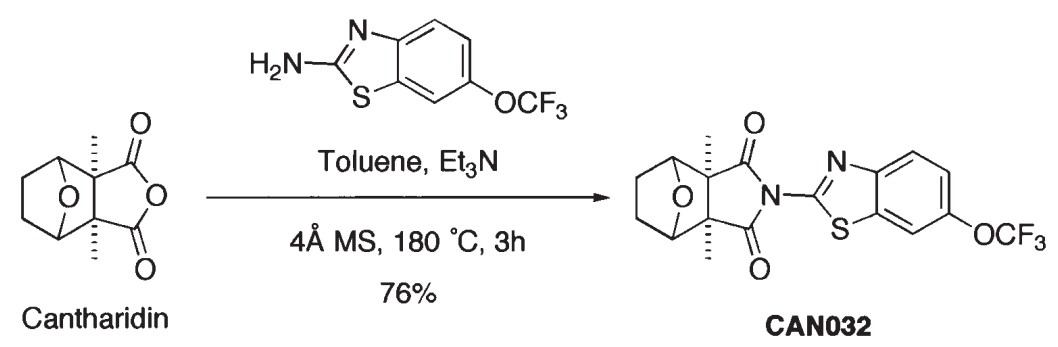

Figure 1. Chemical synthesis scheme of CAN 032.

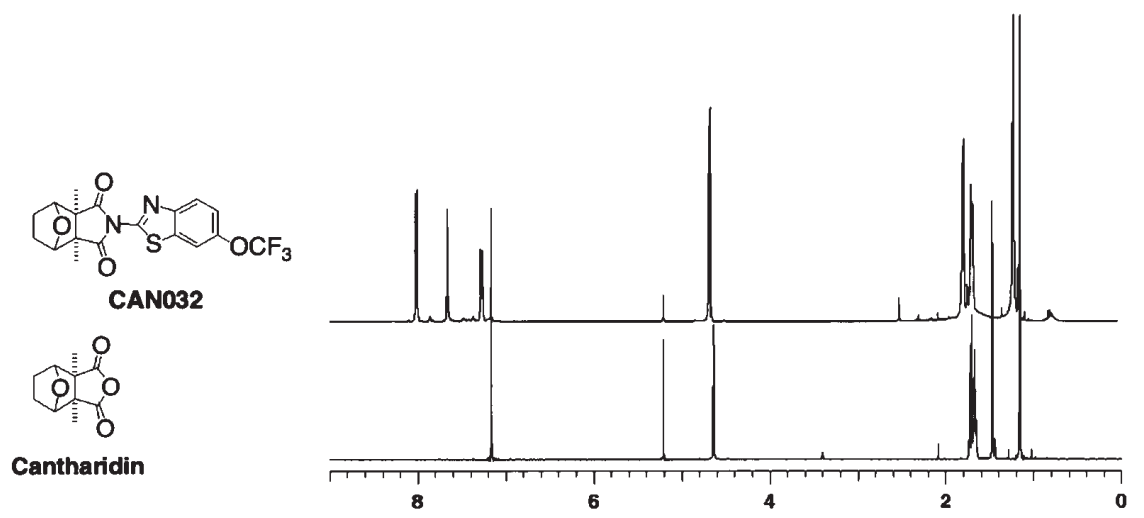

Figure 2. ${ }^{1} \mathrm{H}$ spectra comparison of $\mathrm{CAN} 032$ with the original cantharidin.

suggested that CAN 032 is a novel cantharidin analogue that could possess comparable activity to its mother compound but with a relatively less toxic effect in vitro.

\section{Materials and methods}

Synthesis of CAN 032. Unless otherwise indicated, all reactions were carried out under a nitrogen atmosphere. NMR spectra were recorded on a Varian $500 \mathrm{MHz}$ Fourier transform spectrometer. ${ }^{1} \mathrm{H}$ and ${ }^{13} \mathrm{C}\left[{ }^{1} \mathrm{H}\right]$ NMR spectra were recorded relative to residual protiated solvent; a positive value of the chemical shift denotes a resonance downfield from TMS. Mass analyses were performed on a Finnigan model Mat 95 ST mass spectrometer. Cantharidin and 2amino-6-(trifluoromethoxy)-benzothiazole were purchased from Sigma-Aldrich. All other chemicals were purchased from commercial suppliers and were used without further purification. Toluene and triethylamine were freshly distilled from sodium under nitrogen. All reactions were monitored by analytical thin-layer chromatography (TLC) on Merck aluminum-precoated plates of silica gel $60 \mathrm{~F}_{254}$ with detection by spraying with $5 \%(\mathrm{w} / \mathrm{v})$ dodecamolybdophosphoric acid in ethanol or $5 \%(\mathrm{w} / \mathrm{v})$ ninhydrin in ethanol and subsequent heating. Merck silica gel 60 (230-400 mesh) was used for flash chromatography.

A mixture of cantharidin (10 mg, $0.051 \mathrm{mmol}), 2$-amino6-(trifluoromethoxy)-benzothiazole $(59.6 \mathrm{mg}, 0.26 \mathrm{mmol}$ ), dried toluene and dried triethylamine $(4 \mathrm{ml} ; 2: 1, \mathrm{v} / \mathrm{v})$ in a sealed tube was heated for $2.5 \mathrm{~h}$ at $180^{\circ} \mathrm{C}$. Concentration followed by flash chromatograph gave the product $(16 \mathrm{mg})$ in $76 \%$ yield: ${ }^{1} \mathrm{H}$ NMR $\left(\mathrm{CDCl}_{3}, 500 \mathrm{MHz}\right), \delta 1.31$ (brs, $\left.6 \mathrm{H}\right)$, 1.75-1.81 (m, 2H), 1.87-1.91 (m, 2H), 4.77-4.78 (m, 2H); 7.36 (dd, J=8.5 and $1 \mathrm{~Hz}, 1 \mathrm{H}), 7.76(\mathrm{~s}, 1 \mathrm{H}), 8.11(\mathrm{~d}, \mathrm{~J}=9.5 \mathrm{~Hz}, 1 \mathrm{H})$; ${ }^{13} \mathrm{C} \mathrm{NMR}\left(\mathrm{CDCl}_{3}\right), \delta$ 13.0, 23.8, 54.3, 84.5, 113.7, 119.4, 120.4, $124.5,146.7,147.5,152.7,178.0$; and MS (ESI) m/z (\%), $413\left(\mathrm{M}^{+}+1,100\right), 435(76)$.

Cell lines and cell culture. Two hepatoma cell lines, Hep3B and SK-Hep-1, were obtained from American Type Culture Collection. Both hepatoma cell lines were maintained in minimum essential medium (JRH Biosciences) supplemented with $10 \%$ of heat inactivated fetal bovine serum (Hyclone) together with antibiotics involving penicillin and streptomycin. Cells were allowed to grow in a humidified cell culture incubator maintained at $5 \%$ carbon dioxide.

Human bone marrow cell collection and isolation. Nonmalignant haematological disorder bone marrow cells were collected from consenting patients by bone marrow aspirate method. A total of three adult subjects were recruited; one male and two females. Immediately after collection, mononuclear cells were enriched by Ficoll-Plaque (General Electricity, Amersham) gradient centrifugation. Cells were washed twice with phosphate-buffered saline and resuspended in complete medium $(5,6)$. Viable cell percentage was then estimated by trypan blue exclusion assay and counted using a haemacytometer as mentioned (7).

[3-(4,5-dimethylthiazol-2-yl)-5-(3-carboxymethoxyphenyl)-2(4-sulfophenyl)-2H-tetrazolium] (MTS) assay. Changes in the cellular viability of cantharidin- and its analogue-treated cells were monitored using the MTS activity assay as reported previously (8-10). Briefly, hepatoma cells (Hep3B and SKHep-1) were seeded at day 0 . After $24 \mathrm{~h}$, the medium was 
changed and various compounds were added at different concentrations while, for bone marrow cells, compounds were added on the same day as seeding. After $48 \mathrm{~h}$ of incubation, the medium was removed, MTS/PMS solution was added and they were incubated for a further $30 \mathrm{~min}$. Afterwards, optical absorbance was determined at $490 \mathrm{~nm}$ according to the user's manual (Promega).

Morphological monitoring of cantharidin- and its analoguetreated cells. Any morphological changes from cantharidinand CAN 032-treated Hep3B and SK-Hep-1 hepatoma cells were recorded by investigation under an inverted microscope at the scheduled time point (11)

DNA fragmentation analysis. After treating Hep3B cells with cantharidin and its analogue, genomic DNA was isolated as mentioned before (12). Genomic DNA was isolated by DNAzol (Invitrogen) according to the manufacturer's instructions. Purified DNA was then separated by running in a $1 \%$ agarose gel stained with ethidium bromide and photographed under ultraviolet illumination.

Cell cycle study. Hep3B hepatocellular carcinoma cells were either treated with vehicle $(0.1 \%$ DMSO) or $5 \mu \mathrm{g} / \mathrm{ml}$ of CAN 032 for $12 \mathrm{~h}$ and then stained with propidium iodide and analysed by using the CellQuest software of a BectonDickinson FACS flow cytometre (13).

\section{Results}

Chemical synthesis of cantharidin analogue. Based on the principal chemical structure of the mother compound, cantharidin, we synthesized CAN 032. Details of the chemical reactions and characterization including the ${ }^{1} \mathrm{H}$ spectra comparison of CAN 032 with the original cantharidin are shown in Figs. 1 and 2 respectively. The CAN 032 was further dissolved in DMSO to a concentration of $50 \mathrm{mg} / \mathrm{ml}$ and a clear solution was obtained. It was stored in aliquot at $-20^{\circ} \mathrm{C}$. For the biological assay, the maximum concentration used for CAN 032 was $25 \mu \mathrm{g} / \mathrm{ml}$, thus making the contribution of solvent always $<0.05 \%$.

Potency of cantharidin and its analogue on hepatoma cell lines. We studied the possible cytotoxic activity of cantharidin analogue by means of MTS assay. As shown in Table I, CAN 032 showed comparable MTS $_{50}$ activity (50\% of MTS reduction ability by the chemically treated cell as compared with control) to cantharidin and cisplatinum on both Hep3B and SK-Hep-1 hepatoma cell lines (Fig. 3).

Toxicity on primary bone marrow culture and morphological investigation. A tolerance test using non-malignant haematological disorder bone marrow was performed for CAN 032 together with the mother compound cantharidin. Bone marrow samples seemed to be less sensitive to CAN 032 than cantharidin (Table II). Cantharidin and CAN 032 began to induce Hep3B cell shrinkage, loss of colony-formation ability and adherent property at a dose of $12.5 \mu \mathrm{g} / \mathrm{ml}$ after a 48 -h incubation (Fig. 4). Approximately half of the cells showed such characteristics at $6.25 \mu \mathrm{g} / \mathrm{ml}$. A similar dose-dependent
Table I. MTS $_{50}$ activity test of a chemically synthetic cantharidin analogue (CAN 032) on Hep3B and SK-Hep-1 hepatoma cell lines.

\begin{tabular}{lc}
\hline & $12.5 \mu \mathrm{g} / \mathrm{ml}>\mathrm{MTS}_{50}>6.25 \mu \mathrm{g} / \mathrm{ml}$ \\
\hline CAN 032 & $* \#$ \\
Cantharidin & $* \#$ \\
Cisplatinum & $* \#$
\end{tabular}

* is the mean $\mathrm{MTS}_{50}$ for Hep3B and \# is the mean $\mathrm{MTS}_{50}$ for SKHep-1. Each experiment was performed in triplicate. Results are the mean of three independent experiments.
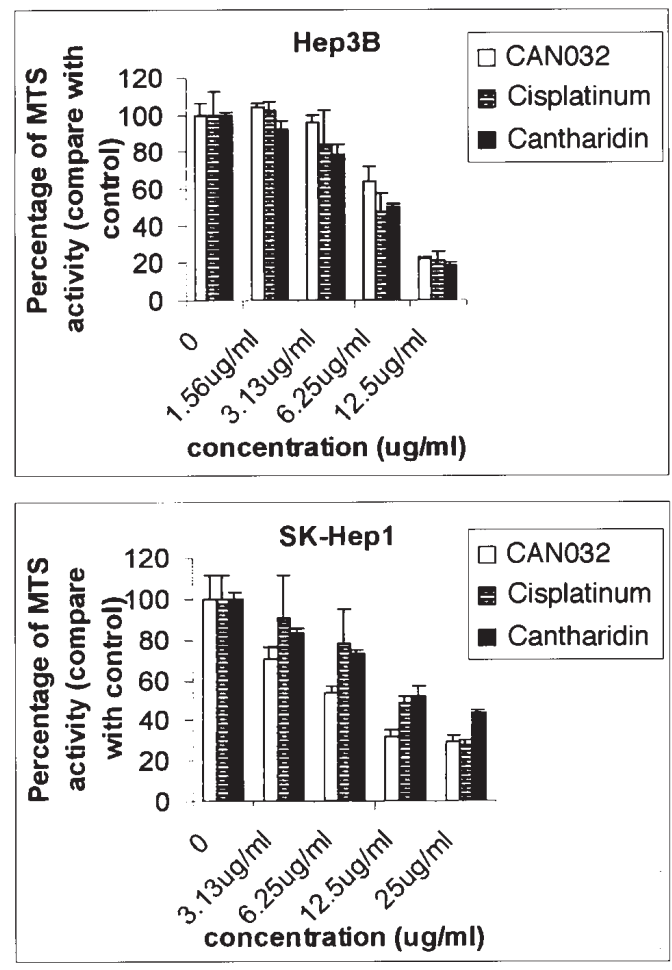

Figure 3. Cytotoxicity assay of cantharidin and CAN 032 on Hep3B and SK-Hep-1 hepatoma cell lines. Hepatoma cells were incubated with different compounds for $48 \mathrm{~h}$ and then assayed. Each experiment was performed in triplicate and a representative result of mean $\pm \mathrm{SD}$ is shown. Similar results were obtained.

Table II. $\mathrm{MTS}_{50}$ activity test of a chemically synthetic cantharidin analogue (CAN 032) on three non-malignant haematological bone marrow cells.

$$
\begin{gathered}
\mathrm{MTS}_{50}>12.5 \mu \mathrm{g} / \mathrm{ml} \quad 12.5 \mu \mathrm{g} / \mathrm{ml}>\mathrm{MTS}_{50}> \\
6.25 \mu \mathrm{g} / \mathrm{ml}
\end{gathered}
$$

\begin{tabular}{ll}
\hline CAN 032 & BM1, BM2, BM3 \\
Cantharidin & BM1, BM2, BM3
\end{tabular}

Each experiment was performed in triplicate. Results are the means of three independent experiments. BM 1 to 3 , three non-malignant haematological bone marrow samples. 


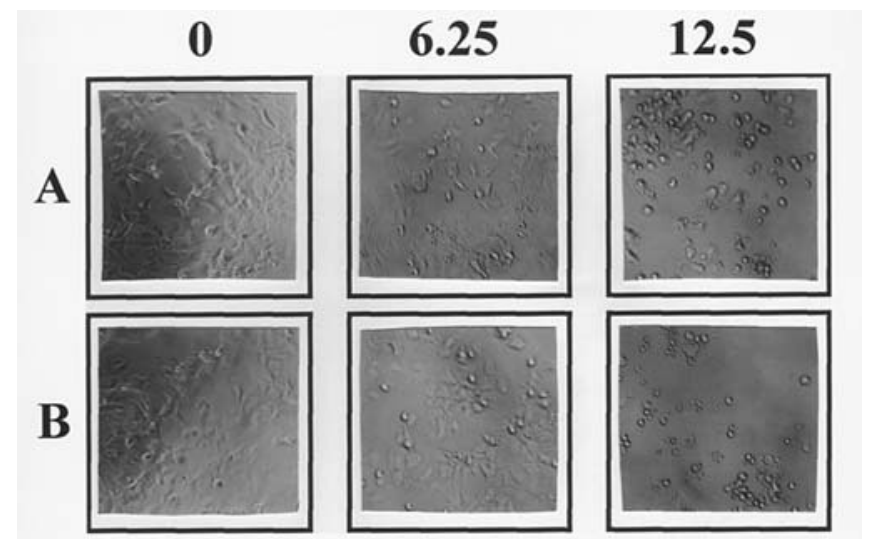

Figure 4. Morphological changes involving cell shrinkage, rounding, and loss of adherent ability and colony-formation property were observed for (A) cantharidin and (B) CAN 032 in a dose-dependent manner in hepatocellular carcinoma Hep3B cells $(6.25 \mu \mathrm{g} / \mathrm{ml}$ and $12.5 \mu \mathrm{g} / \mathrm{ml})$.

relationship of cantharidin and CAN 032 on SK-Hep-1 was also observed (data not shown).

Induced-DNA laddering formation and cell cycle study. As shown in Fig. 5A, CAN 032 induced a dose-dependent formation of DNA fragmentation on the Hep3B hepatocellular carcinoma cells after $48 \mathrm{~h}$ of incubation. CAN 032 also reduced the $G_{1}$ peak of Hep3B cells (Fig. 5B).

\section{Discussion}

Naturally occurring products provide us with numerous of medicinal resources (14). Many drugs that are currently clinically used are actually synthesized from compounds that could be isolated from animal or herbal extracts. Based on the principle chemical structure of cantharidin, we have synthesized a new cantharidin analogue, CAN 032. We further screened its possible cytotoxic activity using two hepatoma cell lines, Hep3B and SK-Hep-1. CAN 032 showed a significant cytotoxic response on both hepatoma cell lines in which the potencies were comparable to that of cantharidin and cisplatinum. Morphologically, cantharidin and CAN 032 showed cytotoxic action on Hep3B cells by inducing loss of colony-formation potential and cell shrinkage.

Since bone marrow suppression and gastrointestinal and urinary tract toxicity are important side effects of cantharidin, we further tested their toxicity on non-malignant haematological bone marrow samples. Bone marrow tolerance analysis suggested that the toxicity of CAN 032 is lower than that of cantharidin.

Induction of DNA fragmentation from intact genomic DNA is a description of apoptosis. Here, we demonstrated that CAN 032 can induce apoptosis in a dose-dependent manner. However, investigation for the mechanism of a potential drug, including the understanding of its signal transduction pathway, is considered to be clinically significant (15). Our preliminary data demonstrated that CAN 032 significantly reduces the $G_{1}$ phase of Hep3B HCC cells. Therefore, we speculated that those cell cycle-related checkpoints would be significant for CAN 032-induced apoptosis and this provided us with an interesting issue for further investigation.
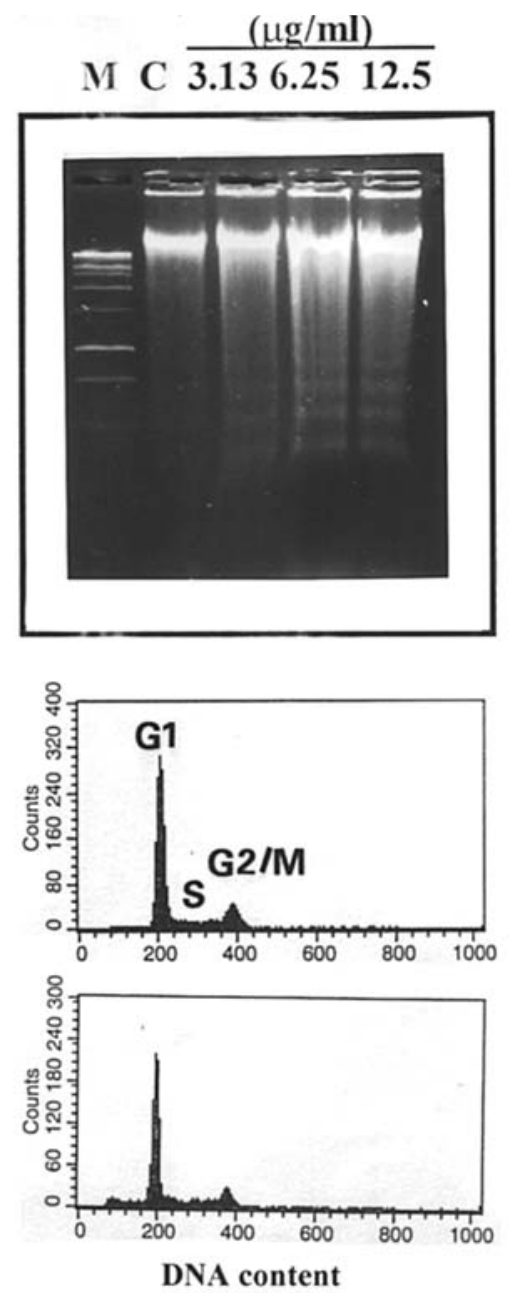

Figure 5. (A) DNA fragmentation analysis further demonstrated that programmed cell death might be a possible description for the activity of CAN 032 on hepatocellular carcinoma Hep3B cells, in a dose-dependent manner. (B) Cell cycle study for the effect of CAN 032 on Hep3B cells (lower) when compared with vehicle (0.1\% DMSO, upper).

We chose Hep3B and SK-Hep-1 hepatoma cell lines as models to study the actions of cantharidin analogues because Hep3B lacks the functional p53 tumour suppressor gene while functional p53 is found in SK-Hep-1. Interestingly, both cell lines seemed to have a similar sensitivity to our cantharidin analogue. It is highly possible that this cantharidin analogue is effective on a large spectrum of p53-positive and -negative hepatoma cells and its anti-cancer activity is independent of p53 status.

Hepatocellular carcinoma remains to be one of the most important solid tumours and it is especially common in subAfrica and East Asia $(16,17)$. The intake of alfatoxin from fungal contaminated crop, inflection of hepatitis B virus and cirrhosis may account for a significant proportion of the causes of hepatocellular carcinoma. Owing to the size and location of the tumours, hepatic resection may not be possible under certain conditions. Thus, any potential chemotherapeutic regimen which could be cytotoxic to the tumour but relatively less toxic to the haemopoietic system would be considered to be beneficial to those patients. As cantharidin is also suggested to be active on leukaemia, further study of the pharmaceutical activity of CAN 032, using leukaemia as a 
demonstration model, is in process in order to elucidate the underlying molecular mechanisms involved.

\section{Acknowledgements}

We acknowledge the support by the Area of Strategic Development (ASD) program of the Hong Kong Polytechnic University (work program A012). The work described in this report was supported by the Areas of Excellence Scheme established under the University Grants Committee of the Hong Kong Special Administrative Region, China (project no. AoE/P-10/01) and a Niche Area Grant offered by the Hong Kong Polytechnic University. C.H.C. and F.Y.L. are the honourary tutors kindly offered by Professors J.J.Y. Sung and G.Y.M. Cheng from the Department of Medicine and Therapeutics, Prince of Wales Hospital, The Chinese University of Hong Kong. S.H.L.K. is supported by the post of 'Research Fellow' kindly offered by Professor A.S.C. Chan. C.H.C. is supported by the post of 'Scientific Officer' kindly offered by Professors K.Y. Wong, S.C.L. Lo, C.P. Lau and A.S.C. Chan of ABCT department. We thank C.H.C. who gave us valuable advice on the anti-cancer drug screening experiments.

\section{References}

1. Leung TWT, Patt YZ, Lau WY, Ho SKW, Yu SC, Chan ATC, Mok TSK, Yeo W, Liew CT, Leung NW, Tang AMY and Johnson PJ: Complete pathological remission is possible with systemic combination chemotherapy for inoperable hepatocellular carcinoma. Clin Cancer Res 5: 1676-1681, 1999.

2. Tsauer W, Lin JG, Lin PY, Hsu FL and Chiang HC: The effects of cantharidin analogues on xanthine oxidase. Anticancer Res 17: 2095-2098, 1997.

3. Zhang S: A study on antitumor chemotherapeutic agents: synthesis of N-cantharidine derivatives. Yao Xue Xue Bao 16: 784-786, 1981

4. Kok SHL, Chui CH, Lam WS, Cheng J, Tang JCO, Lau FY, Cheng GYM, Wong RSM and Chan ASC: Induction of apoptosis on carcinoma cells by two synthetic cantharidin analogues. Int $\mathbf{J}$ Mol Med 17: 151-157, 2006.

5. Chow LMC, Chui CH, Tang JCO, Teo I, Lau FY, Cheng GYM, Wong RSM, Leung TWT, Lai KB, Yau M, Gou D and Chan ASC: Gleditsia sinensis fruit extract is a potential chemotherapeutic agent in chronic and acute myelogenous leukemia. Oncol Rep 10: 1601-1607, 2003.
6. Lau FY, Chui CH, Gambari R, Kok SHL, Kan KL, Cheng GYM, Wong RSM, Teo ITN, Cheng CH, Wan TSK, Chan ASC and Tang JCO: Antiproliferative and apoptosis-inducing activity of Brucea javanica extract on human carcinoma cells. Int J Mol Med 16: 1157-1162, 2005.

7. Chow LMC, Chui CH, Tang JCO, Lau FY, Yau MYC, Cheng GYM, Wong RSM, Lai PBS, Leung TWT, Teo ITN, Cheung F, Guo D and Chan ASC: Anti-angiogenic potential of Gleditsia sinensis fruit extract. Int J Mol Med 12: 269-273, 2003.

8. Chui CH, Cheng GYM, Ke B, Lau FY, Wong RSM, Kok SHL, Fatima S, Cheung F, Cheng CH, Chan ASC and Tang JCO: Growth inhibitory potential of effective microorganism fermentation extract (EM-X) on cancer cells. Int J Mol Med 14: 925-929, 2004.

9. Cheung F, Chui CH, Chan ASC, Lau FY, Cheng GYM, Wong RSM, Kok SHL, Teo ITN, Cheng CH and Tang JCO: Inhibition of proteasome activity in Gleditsia sinensis fruit extract-mediated apoptosis on human carcinoma cells. Int J Mol Med 16: 925-929, 2005.

10. Teo ITN, Chui CH, Tang JCO, Lau FY, Cheng GYM, Wong RSM, Kok SHL, Cheng CH, Chan ASC and Ho KP: Antiproliferation and induction of cell death of Phaffia rhodozyma extract fermented by brewer malt waste on breast cancer cells. Int J Mol Med 16: 931-936, 2005.

11. Chui CH, Lau FY, Tang JCO, Kam KL, Cheng GYM, Wong RSM, Kok SHL, Lai PBS, Ho R, Gambari R and Chan ASC: Activities of fresh juice of Scutellaria barbata and warmed water extract of Radix Sophorae Tonkinensis on antiproliferation and apoptosis of human cancer cell lines. Int J Mol Med 16: 337-341, 2005

12. Chow LMC, Tang JCO, Teo ITN, Chui CH, Lau FY, Leung TWT, Cheng G, Wong RSM, Wong ILK, Tsang KMS, Tan WQ, Zhao YZ, Lai KB, Lam WH, Guo DA and Chan ASC: Antiproliferative activity of the extract of Gleditsia sinensis fruit on human solid tumour cell lines. Chemotherapy 48: 303-308, 2002.

13. Chui CH, Lau FY, Chan ASC, Cheng GYM, Wong RSM, Lai KB, Kok SHL, Au Yeung TTL, Teo ITN, Yau MYC, Cheung F, Cheng CH and Tang JCO: Gleditsia sinensis fruit extract-induced apoptosis involves changes of reactive oxygen species level, mitochondrial membrane depolarization and caspase 3 activation. Int J Mol Med 15: 539-543, 2005.

14. Chui CH, Gambari R, Lau FY, Teo ITN, Ho KP, Cheng GYM, Ke B, Higa T, Kok HL, Chan ACS and Tang JCO: Anti-cancer potential of traditional Chinese herbal medicines and microbial fermentation products. Minerva Biotec 17: 183-191, 2005.

15. Yang NS, Shyur LF, Chen CH, Wang SY and Tzeng CM: Medicinal herb extract and a single-compound drug confer similar complex pharmacogenomic activities in MCF-7 cells. J Biomed Sci 11: 418-422, 2004.

16. Harris CC: Hepatocellular carcinogenesis: recent advances and speculation. Cancer Cells 2: 146-148, 1990.

17. Okuda K: Hepatocellular carcinoma: recent progress. Hepatology 15: 948-963, 1992. 